\title{
PREVALÊNCIA DA MASTITE BOVINA CAUSADA POR Prototheca zopfii EM REBANHOS LEITEIROS, NA REGIÃO NORTE DO PARANÁ
}

\author{
PREVALENCE OF BOVINE MASTITIS DUE TO Prototheca zopfii \\ IN DAIRY CATTLE IN NORTH PARANÁ, BRAZIL
}

\author{
Laerte Francisco Filippsen ${ }^{1}$ Fernanda Barros Moreira ${ }^{2}$ \\ Adauto Taiti Sakashita ${ }^{2}$ Daniéla Regina Bittencourt ${ }^{2}$
}

\section{RESUMO}

Algas do gênero Prototheca têm sido relacionadas como agente etiológico na ocorrência de mastite bovina, entretanto, nenhum caso foi relatado no estado do Paraná. O presente trabalho objetivou determinar a prevalência desta alga, enquanto agente etiológico nas mastites bovinas, em rebanhos leiteiros, na região norte do Paraná. Foram visitadas 20 propriedades produtoras de leite e realizados exames clínicos e teste do CMT (California Mastitis Test) em todos os animais em lactação. A alga Prototheca zopfii foi isolada de dois animais de uma das propriedades. Todas as cepas isoladas de Prototheca zopfii mostraram-se resistentes aos antimicrobianos testados.

Palavras-chave: Prototheca zopfii, mastite bovina, alga.

\section{SUMMARY}

Prototheca has been reported as an etiological agent in the occurrence of bovine mastitis, although no case has been noticed in Paraná. The aim of this work was to determine the prevalence of this algae as an etiological agent of the bovine mastitis in dairy cattle in north Paraná. Clinical exams and CMT (California Mastitis Test) were done in all lactation animals raised in 20 dairy farms. The algae Prototheca zopfii was found in two animals of one farm. All the Prototheca zopfii strains were resistent against the antimicrobial agents tested.

Key words: Prototheca zopfii, bovine mastitis, algae.

\section{INTRODUÇÃO}

A mastite bovina é uma das principais enfermidades que acometem os rebanhos leiteiros, sendo considerada um dos maiores empecilhos à sua exploração lucrativa. As maiores perdas causadas pela mastite são devidas à diminuição na produção de leite, depreciação na qualidade nutritiva, custo de tratamento, custo de atendimento veterinário e laboratorial e perdas no potencial genético (DOBBINS, 1977).

Vários microorganismos são citados como agentes etiológicos da mastite bovina. A ocorrência de mastite bovina ocasionada por Prototheca sp., uma alga aclorofilada, tem sido relatada por diversos autores (ANDERSON \& WALKER, 1988; HODGES et al., 1985; SPALTON, 1985). O gênero Prototheca foi primeiramente descrito por KRÜEGER em 1894 e, embora esta alga ocorra como um saprófita ambiental, pode também causar doenças em humanos e animais (KAPLAN, 1977; McDONALD et al., 1984b). No Brasil, casos clínicos isolados e surtos de mastite bovina devido à Prototheca sp. foram descritos nos Estados de São Paulo, Minas Gerais e Mato Grosso do Sul (COSTA et al.,1995; COSTA et al. 1996a). No Paraná, não há trabalhos relacionando esta alga com casos de mastite bovina. O presente trabalho teve por objetivo verificar a prevalência de Prototheca zopfii como agente etiológico da mastite bovina em rebanhos leiteiros na região norte do Paraná, bem como determinar a suscetibilidade in vitro deste microorganismo frente a diversos antimicrobianos.

\footnotetext{
${ }^{1}$ Médico Veterinário, Doutor, IAPAR, Laboratório de Microbiologia Animal, Caixa Postal 481, 86001-970, Londrina, PR. E-mail: laerte@pr.gov.br. Autor para correspondência.

${ }^{2}$ Bolsistas CNPq/PIBIC-IAPAR. 


\section{MATERIAL E MÉTODOS}

Foram realizadas visitas a 20 propriedades produtoras de leite da região norte do Paraná, das quais 18 eram produtoras de leite $\mathrm{C}$, uma propriedade produtora de leite tipo B e uma produtora de leite tipo A. Todas as propriedades foram visitadas duas vezes no período de 1995 a 1996. Em cada visita, foram realizados exames clínicos e prova do "California Mastitis Test" (SCHALM \& NOORLANDER, 1957) em todas as vacas em lactação, para identificação dos animais que apresentavam mastite subclínica. De todos os quartos mamários positivos ao CMT e de todos os quartos mamários com mastite clínica foram coletadas amostras duplas de leite. Estas amostras foram enviadas ao laboratório, sob refrigeração, para a realização de exames microbiológicos, segundo metodologias recomendadas (COWAN \& STEEL, 1975; CARTER, 1978; IDF, 1987; NMC, 1990). As amostras duplas de leite foram semeadas em ágar sangue (Merck), ágar EMB (Oxoid) e ágar batatadextrose (Biobrás), e incubadas, em aerobiose, a $37^{\circ} \mathrm{C}, 24-48 \mathrm{~h}$. Os microorganismos foram identificados e classificados segundo Bergey's Manual of Systematic Bacteriology (KRIEG \& HOLT, 1984). A identificação da Prototheca zopfii foi realizada pelas características morfológicas macro e microscópicas, utilização de carboidratos (PORE, 1985) e resistência ao clotrimazole $(50 \mu \mathrm{g})$ (CASAL \& GUTIERREZ, 1983). O teste de sensibilidade antimicrobiana foi realizado segundo técnica de KirbyBauer (BARRY \& THORNSBERRY, 1980), utilizando-se os seguintes discos de antimicrobianos: ampicilina $(10 \mu \mathrm{g})$, bacitracina (10UI), cefadroxil $(30 \mu \mathrm{g})$, cefalotina $(30 \mu \mathrm{g})$, cloranfenicol $(30 \mu \mathrm{g})$, eritromicina $(15 \mu \mathrm{g})$, estreptomicina $(10 \mu \mathrm{g})$, gentamicina $(10 \mu \mathrm{g})$, canamicina $(30 \mu \mathrm{g})$, neomicina $(30 \mu \mathrm{g})$, nitrofurantoína $(300 \mu \mathrm{g})$, novobiocina $(5 \mu \mathrm{g})$, penicilina $(10 \mathrm{UI})$, sulfazotrim $(25 \mu \mathrm{g})$ e tetraciclina

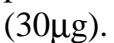

\section{RESULTADOS E DISCUSSÃO}

Um total de 618 vacas em lactação foram clinicamente examinadas. Destas, 2371 quartos mamários foram avaliados pelo teste CMT. Foram coletadas amostras duplas de leite de 1319 quartos, cujos resultados dos exames microbiológicos encontram-se na Tabela 1. Seiscentos e sessenta amostras foram positivas nos exames microbiológicos. Os microorganismos mais freqüentemente isolados neste estudo foram: Corynebacterium bovis (33,03\%), Staphylococcus coagulase negativa $(31,97 \%)$ e Staphylococcus aureus $(25 \%)$, seguidos do Streptococcus uberis $(3,48 \%)$, Actinomyces

Tabela 1 - Freqüência dos agentes etiológicos isolados de
mastite bovina em rebanhos leiteiros, na região
norte do Paraná, no período de 1995 a 1996.

pyogenes (3,03\%), Streptococcus dysgalactiae (1,52\%), Streptococcus agalactiae (0,61\%), Streptococcus bovis $(0,61 \%)$, Prototheca zopfii $(0,45 \%)$ e Pseudomonas sp. (0,3\%). A alga Prototheca zopfii foi isolada de três $(0,45 \%)$ amostras duplas de leite de duas vacas de uma mesma propriedade. Um dos animais apresentava mastite clínica em somente um dos quartos (posterior direito). O outro animal apresentava mastite subclínica (CMT +++) nos quartos anterior direito e anterior esquerdo. Ambos animais eram autóctones. As colônias de Prototheca, em cultivo puro, puderam ser identificadas em ágar batata-dextrose, após 24 horas de incubação. Esfregaços corados com azul de metileno a $1 \%$ permitiram a visualização de células ovóides e com formação de endosporos. Nas provas de utilização de carboidratos, as amostras de Prototheca zopfii apresentaram resultados positivos para glicose, frutose, 2-propanol, acetato (pH5,0) e glicerol, e negativos para lactose, sacarose, trealose, xilose e manose. Todas as amostras apresentaram resistência ao clotrimazole. Casos esporádicos e surtos de mastite bovina por Prototheca sp. já foram relatados em outros Estados (COSTA et al., 1995; COSTA et al., 1996a; COSTA et al., 1996b), sendo este o primeiro trabalho comprovando a ocorrência de Prototheca zopfii, como agente etiológico de mastite bovina em rebanhos leiteiros paranaenses. Testes in vitro têm demonstrado suscetibilidade deste agente etiológico somente a alguns antimicrobianos. Entretanto, nenhum resultado efetivo foi obtido em testes in vivo (TARTE $\boldsymbol{e}$ t al., 1991; LAGNEAU, 1996). As três cepas de Prototheca zopfii isoladas, neste trabalho, mostraram-se resistentes a todos os antimicrobianos testados in vitro. Como este microorganismo não responde a terapias de rotina, é recomendado, como melhor método de controle da doença, a eliminação dos animais infectados (KIRK, 1991; LAGNEAU, 
1996). Embora a freqüência desta alga como agente etiológico nos rebanhos estudados tenha sido baixa, é pertinente que seja dada atenção a este microorganismo nos estudos epidemiológicos da mastite bovina e exames laboratoriais de rotina, principalmente por ser um saprófita ambiental e que apresenta resistência a maioria dos antimicrobianos, como comprovado neste trabalho e de outros autores (McDONALD et al. 1984a, LAGNEAU, 1996). As algas do gênero Prototheca podem ser facilmente isoladas em meios de ágar batata-dextrose, Sabouraud e ágar milho. Técnicas de coloração com azul de metileno permitem sua diferenciação dos fungos leveduriformes, pela visualização de células hialinas, ovóides e/ou globosas, com a formação de esporângios com endosporos no seu interior (PORE, 1985; PAL et al., 1990).

\section{REFERÊNCIAS BIBLIOGRÁFICAS}

ANDERSON, K.L., WALKER, R.L. Sources of Prototheca spp. in a dairy herd environment. Journal of the American Veterinary Medicine Association, v. 193, p. 553-556, 1988.

BARRY, A.L., THORNSBERRY,C. Susceptibility testing: diffusion test procedures. In: LENNETHE, E.H. Manual of Clinical Microbiology, 4. ed. 1985, p. 978-987.

CARTER, G.R. Diagnostic procedures in Veterinary Microbiology. 2. ed. Illinois, U.S.A: Charles C. Thomas, $1978,362 \mathrm{p}$.

CASAL, M.J., GUTIERREZ, J. Simple new test for rapid differentiation of Prototheca wickerhamii from Prototheca zopfii. Journal of Clinical Microbiology, v. 18, n. 4, p. 992993, 1983.

COWAN, S.T., STEEL, K.J. Manual for the identification of medical bacteria. 2. ed. Cambridge: University Press, 1975, 238 p.

COSTA, E.O. da, BENITES, N.R., MELVILlE, P.A. $\boldsymbol{e} \boldsymbol{t}$ al. Estudo etiológico da mastite clínica bovina. Revista Brasileira de Medicina Veterinária, v. 17, n. 4, p. 156-158, 1995.

COSTA, E.O., CARCIOFI, A.C., MELVILlE, P.A. et al. Prototheca sp. outbreak of bovine mastitis. Journal Veterinary Medicine, B, v. 43, p. 321-324, 1996a.

COSTA, E.O. da, RIBEIRO, A.R., WATANABE, E.T. $\boldsymbol{e}$ t al. An increased incidence of mastitis caused by Protoheca species and Nocardia species on a farm in São Paulo, Brazil. Veterinary Research Communications, v. 20, p. 237-241, 1996b.

DOBBINS JR, C.N. Mastitis losses. Journal of the American Veterinary Medicine Association, v. 170, n. 10, p. 1129 1132, part 2, 1977.
HODGES, R.T., HOLLAND, J.T.S., NEILSON, F.J.A. $\boldsymbol{e}$ t al. Prototheca zopfii mastitis in a herd of dairy cows. New Zealand Veterinary Journal, v. 33, p. 108-111, 1985.

INTERNATIONAL DAIRY FEDERATION. Bovine mastitis. Definition and guidelines for diagnosis. Bulletin 211. 24 p. 1987.

KAPLAN, W. Protothecosis and infections caused by morphologically similar green algae. In: THE INTERNATIONAL CONFERENCE ON THE MYCOSES, 4. Proceedings... PAHO Scientific Publication, n. 356, 1977, p. 218-232.

KIRK, J.H. Diagnosis and treatment of difficult mastitis cases. Agri-practice, v. 12, p. 15-20, 1991.

KRIEG, N.R., HOLT, J.C. Bergey's manual of systematic bacteriology. Baltimore: Williams \& Wilkins, 1984, 1600 p.

KRÜEGER, W. Beiträge zur Kenntniss der Organismen des Saftflusses (sog. Schlemflusses) der Laubbäume. Zopf's Beiträge. Physiologie und Morphologie, v. 4, p. 69-116, 1894.

LAGNEAU, P.E. First isolation of Prototheca zopfii in bovine mastitis in Belgium. Journal de Mycologie Medicale, v. 6, n. 3, p. 145-148, 1996.

McDONALD, J.S., RICHARD, J.L., ANDERSON, A.J. Antimicrobial susceptibility of Prototheca zopfii isolated from bovine intramammary infections. American Journal of Veterinary Research, v. 45, n. 6, p. 1079-1080, 1984a.

McDONALD, J.S., RICHARD, J.L., CHEVILLE, N.J. et al. Colorless alga can pollute water, cause mastitis. Agricultural Research, USA, v. 32, n. 7, p. 4-5, 1984 b.

NATIONAL MASTITIS COUNCIL. Microbiological procedures for the diagnosis of bovine udder infection. National Mastitis Council, 1990. 34 p.

PAL, M., HASEGAWA, A., ONO, K. et al. A new staining solution for the morphological studies of fungi and Prototheca. Japanese Journal of Veterinary Science, v. 52, n.3, p. 527-531, 1990.

PORE, R.S. Prototheca taxonomy. Mycopathologia, v. 90, p. 129-139, 1985.

SCHALM, O.M., NOORLANDER, D.D. Experiments and observations leading to development of the California Mastitis Test. Journal of American Veterinary Research, v. 130, n. 5, p. 199-204, 1957.

SPALTON, D.E. Bovine mastitis caused by Prototheca zopfii: a case study. Veterinary Record, v. 116, p. 347-349, 1985.

TARTE, M., BECERRA, T., ALVAREZ, O.S. et al. Clinical mastitis in a cow caused by Prototheca sp. Notas Veterinárias, v.1, p. 17-19, 1991. 